\title{
O lugar do patrimônio na operação historiográfica e o lugar da história no campo do patrimônio
}

Zita Rosane Possamai"

Resumo: Esse artigo propõe algumas reflexões sobre o lugar do patrimônio na operação historiográfica e o lugar da história, como escrita e ação, no campo do patrimônio, a partir da divisão do texto em três momentos. Inicialmente são feitos apontamentos sobre a imbricação da história e dos historiadores com as práticas patrimoniais no Brasil, com indagações sobre afastamentos e aproximações entre esses campos. Em um segundo momento são apresentados os resultados de levantamento da produção acadêmica brasileira sobre o patrimônio, entre os anos de 1999 e 2011, especialmente no âmbito dos estudos históricos em nível de pós-graduação. Finalmente, é problematizado o conceito de campo do patrimônio e campo político para pensar os agentes envolvidos com a questão. Conclui que os historiadores estiveram envolvidos com as questões do patrimônio, desde o surgimento dos primeiros museus brasileiros, no século XIX, quando esteve em voga uma determinada escrita da história associada aos Institutos Históricos e Geográficos e que, em décadas recentes, o patrimônio foi retomado pela história acadêmica como objeto de investigação e ação política. Palavras-chave: Patrimônio. Escrita da história. Museus. Campo.

Professora associada da Universidade Federal do Rio Grande do Sul/ UFRGS. Coordenadora do Programa de Pós-Graduação em Museologia e Patrimônio da UFRGS. Doutora em História com pós-doutoramento na Universidade Paris 3 Sorbonne Nouvelle. Bolsista de Produtividade do CNPq. E-mail: zitapossamai@gmail.com, http://orcid.org/0000-0003-4014-5389

Anos 90, Porto Alegre, v. 25, n. 48, p. 23-49, dez. 2018 
O lugar do patrimônio na operação historiográfica e o lugar da história...

\section{Introito}

Esta escrita está relacionada a uma preocupação e reflexão sobre o lugar do patrimônio na operação historiográfica (CERTEAU, 2011), e o lugar da história, como escrita e ação, no campo do patrimônio. Os apontamentos que farei estão diretamente vinculados a um lugar social (CERTEAU, 2011) de alguém que se posicionou e se posiciona justamente nesses dois espaços. Por um lado, como investigadora do patrimônio, seja numa acepção mais estrita da história das práticas e representações relacionadas à preservação dos bens edificados e museológicos; seja num espectro mais amplo de reflexão sobre as relações entre os sujeitos e suas memórias configuradas na busca pela perpetuação de traços do vivido. Nesse espaço, insistentemente ocupado, o sentimento que vivenciei era o de outsider, por pesquisar objeto ainda estranho à historiografia e cuja aceitação era marcada pela resistência por parte dos pares. Por outro lado, coloquei-me como agente técnico e político num campo do qual a História parecia estar excluída ou alheia (se compararmos a outros ofícios, tais como o da Arquitetura, por exemplo) das problemáticas que implicavam justamente atribuir valor de ordem histórica ou decidir sobre matéria atinente ao passado e cuja competência seria ou deveria ser justamente dos historiadores. Assim, minhas reflexões iniciam com apontamentos sobre a imbricação da história e dos historiadores com as práticas patrimoniais no Brasil, com indagações sobre afastamentos e aproximações entre esses campos; passam por dados relativos à produção acadêmica sobre patrimônio no Brasil em anos recentes e finalizam com a problematização do conceito de campo para pensar os agentes envolvidos com a questão e suas relações com a participação política.

\section{O lugar da história no campo do patrimônio no Brasil}

Vários estudos históricos sobre o Patrimônio no Brasil focaram-se na análise da atuação dos órgãos estatais, a exemplo do Serviço do Patrimônio Histórico e Artístico Nacional (SPHAN) 
(GONÇALVES, 1996; FONSECA, 1997; CHUVA, 2009). Entretanto, muito antes que o termo patrimônio fosse usado no Brasil, as primeiras práticas patrimoniais em nosso território foram caracterizadas pela coleta, pesquisa, classificação e exposição de coleções e tiveram seu espaço no primeiro museu brasileiro, o Museu Real, posteriormente, denominado Museu Nacional.

Foi justamente nessa instituição, que as primeiras práticas de escrita da história receberam acolhimento. O Instituto Histórico e Geográfico Brasileiro (IHGB), considerado como um dos primeiros movimentos de construção de um saber e de uma escrita da história no Brasil (GUIMARÃES, 1988), fora criado a partir da iniciativa da Sociedade Auxiliadora da Indústria Nacional, que mantinha estreita relação com o Museu Nacional (LOPES, 2005). No Paço da Cidade, lugar simbólico que marcava o vínculo da iniciativa com o Império, presidiu a assembleia que decidiu pela criação da entidade o então diretor desse museu, assim como as primeiras reuniões do IHGB realizaram-se nos espaços daquela instituição. Nesse sentido, a entidade que congregou aqueles que tomaram a si a tarefa de escrita de uma determinada história, na primeira metade do século XIX, teve como espaço de suas reuniões a instituição que, naquele contexto, continha as nuances de um museu metropolitano de caráter universal e enciclopédico e que privilegiava as ciências naturais e etnográficas como áreas de especialização (LOPES, 2005).

É interessante observar que o IHGB também se preocupou em criar um museu para reunir os mais variados objetos provenientes da natureza e que mostrassem o grau civilizatório da nação, em termos de seus costumes e suas possibilidades econômicas. Se inicialmente o Instituto configurou seu gabinete de história natural, reunindo inclusive coleções etnográficas, ao longo das décadas seu acervo foi se especializando para documentos/monumentos, tais como a medalhas, configurando com o Museu Nacional "uma divisão no campo da administração da memória material da Nação" (BITENCOURT, 2005).

Saindo da Corte, ao lado do Museu Nacional e do IHGB, o Museu Paraense, o Museu Paulista e o Museu Paranaense constituíram-se nas primeiras instituições científicas aqui instaladas com o propósito de coletar, reunir e produzir conhecimento sobre as 
riquezas naturais e dos povos no Brasil (LOPES, 2005; SANJAD, 2010; CARNEIRO, 2013). Inseridos numa rede internacional dos museus de ciências do século XIX (LOPES; MURRIELO, 2005), essas instituições estavam em sintonia com os pressupostos científicos positivistas e evolucionistas, a partir dos quais as riquezas naturais interessavam para fins de conhecimento científico e de exploração econômica e onde o estudo dos povos autóctones subordinava-se ao viés biológico, característica da configuração dos estudos etnológicos naquele contexto (SCHWARCZ, 2005).

Vestígios e documentos relacionados à história compunham, nesses museus, apenas mais uma das seções ou coleções entre aquelas de Zoologia, Botânica, Mineralogia, Etnografia, Arqueologia. Pelo menos até as primeiras décadas do século XX, nessas instituições, e em outras que foram criadas nos mesmos moldes enciclopédicos, como o Museu Júlio de Castilhos no Rio Grande do Sul, o maior investimento era direcionado à constituição das ciências naturais. A partir da matriz produzida pelo IHGB e disseminada em diversas províncias brasileiras, através dos institutos estaduais, outras iniciativas de escrita da história configuraram-se. Em vários contextos regionais do Brasil, especialmente a partir dos anos 1920, os museus foram estabelecidos como local de levantamento, reunião, criação e exposição de vestígios materiais, escritos e visuais do passado local e nacional.

Em São Paulo, ao assumir a direção do Museu Paulista, em 1917, Affonso de Taunay encontrou nos espaços do Palácio de Bezzi, monumento à Independência erigido em 1895, locus propício para inaugurar a guinada à história daquela instituição novecentista, concebida preliminarmente com predominância das ciências naturais. No Museu, Taunay deu vazão à matriz teórica forjada no Instituto Histórico e Geográfico de São Paulo, na qual a História do Brasil confundia-se com a história paulista e onde os bandeirantes foram associados a uma raça de heróis míticos cuja ação de desbravamento no interior do território brasileiro proporcionara a configuração e integração nacional. Segundo Ana Fonseca Brefe (2005), a partir de uma vertente historiográfica em estreito diálogo com Capistrano de Abreu, Taunay estruturou nos espaços expositivos uma narrativa visual da história com característica descritiva, linear, evolutiva e 
episódica, solidamente amparada em documentos escritos e na produção de imagens visuais. Em perspectiva teleológica, a disposição de retratos e esculturas no espaço arquitetônico encenava uma performance cujo final consagrava São Paulo como o criador da nação (BREFE, 2005). Ainda hoje, o Museu Paulista se configura como um dos únicos documentos disponíveis de feições museológicas para vislumbre de uma escrita visual da história, a partir da perspectiva dos pensadores ligados aos institutos históricos e geográficos.

O Museu Mineiro, criado junto ao Arquivo Público Mineiro em 1895, inicialmente, situou-se em consonância com o viés enciclopedista dos museus desse período e tendo "[...] a missão de inventariar as riquezas naturais, os talentos e as obras de homens de Minas, assegurando o reconhecimento das potencialidades, riquezas e tradições da 'pátria mineira"' (JULIÃO, 2010, p. 295). Semelhante ao processo que ocorrera com o Museu Paulista e com o Museu Júlio de Castilhos, a partir da década de 1920, e tendo Gustavo Penna como um dos seus principais idealizadores, o Museu Mineiro passou a se dedicar exclusivamente à celebração do passado de Minas, inscrito no movimento de valorização do barroco mineiro como patrimônio da nação brasileira pelos modernistas. A orientação histórica do Museu Mineiro se fortaleceu nas décadas de 1930 e 1940, sobretudo no Estado Novo, conjuntura em que a construção de uma identidade nacional fez parte das políticas de Estado (JULIÃO, 2010).

Descendo ao Sul do Brasil, o Museu Paranaense, criado em 1876 como museu de história natural com o propósito de exibir as riquezas naturais da província, agregou às suas seções artefatos indígenas e arqueológicos, bem como retratos e documentos históricos pertencentes a personagens políticos, como Dom Pedro II, ou acontecimentos locais, como a Revolução Federalista. Conforme Cíntia Braga Carneiro (2013), em 1902, assumiu a direção do museu o historiador, fundador e idealizador do Instituto Histórico e Geográfico Paranaense Romário Martins. Articulando ambas as instituições, Romário Martins atuou no sentido de idealizar uma memória e uma identidade regional com o objetivo de distinguir o Paraná das demais províncias brasileiras, através da valorização 
de suas riquezas naturais e da elaboração de uma representação da população como ordeira, disciplinada, empreendedora e civilizada.

No Rio Grande do Sul, a estreita relação entre o Arquivo Público, o Instituto Histórico e Geográfico e o Museu Júlio de Castilhos direcionou a guinada à história da principal instituição museológica do estado, criado nos mesmos moldes enciclopédicos dos primeiros museus novecentistas brasileiros. A partir de 1925, o museu recebeu a Seção Histórica do Arquivo Público do estado e o recém-criado Instituto Histórico e Geográfico do Rio Grande do Sul. Atuando em conjunto, os três órgãos passaram a dedicar-se às práticas de levantamento, coleta, compilação e divulgação de documentos históricos, especialmente sobre a ocupação do território e as operações militares na região. Com destaque à atuação de Eduardo Duarte e Aurélio Porto, esses pesquisadores empreenderam o que denominaram de "cruzada" na busca de documentos com vistas à escrita da história do estado, de acordo com os moldes metódicos preconizados no contexto. Entretanto, além da atenção aos escritos, esses pesquisadores voltaram-se à busca, recebimento ou confecção de artefatos e imagens (álbuns fotográficos, esculturas e pinturas) relacionados especialmente aos episódios da guerra farrapa, tendo em vista que tiveram sob sua responsabilidade a montagem de uma das seções da Exposição do Centenário da Revolução Farroupilha de 1935 (NEDEL, 1999; POSSAMAI, 2013; SILVA, 2018).

Entretanto, todos esses movimentos de escrita da história tiveram assento no interior dos museus enciclopédicos, fundados com matizes vinculados às ciências naturais no século XIX ou início do século XX, e que reorientavam seus propósitos para a celebração do passado. Diferentemente, o Museu Histórico Nacional nascera com a função histórica na sua concepção. Gustavo Barroso, também membro do Instituto Histórico e Geográfico Brasileiro, foi seu principal idealizador e esteve à frente da instituição por diversas décadas e tem sido exaustivamente investigado. Como mostram vários estudos (MAGALHÃES, 2006; CHAGAS, 2009; SANTOS, 2006; ABREU, 1996; FARIA, 2017), diferente da perspectiva linear e episódica de Taunay, Gustavo Barroso concebia os objetos como autênticas relíquias pretéritas, capazes de fazer evocar o culto da saudade e ensinar o povo a amar o passado. A perspectiva científica 
de esquadrinhamento das minúcias amparava-se na tradição antiquária, na qual importava verificar a autenticidade dos objetos, daí a relevância de estudar especialmente moedas, selos, brasões, medalhas, prioritariamente pertencentes a membros militares ou da nobreza imperial (SANTOS, 2006; ABREU, 1996; MAGALHÃES, 2006; AUTOR, 2013).

Esse breve percurso segue algumas pistas no sentido de evidenciar que as práticas de escrita da história empreendidas por esses sujeitos, sempre estiveram intimamente vinculadas às práticas de colecionamento, de conservação, de pesquisa e de exposição dos traços do passado, aos quais foi atribuído o sentido de patrimônio da nação nos moldes do projeto dos modernistas e do SPHAN. A esses primeiros "homens de letras" (GOMES, 2013, p. 38) e "homens de museus" interessava coletar, reunir e compilar documentos escritos ou visuais com o objetivo de escrita de uma narrativa sobre o passado calcada em determinados aspectos julgados mais relevantes, tais como a ocupação territorial, a disputa das fronteiras, as efemérides, entre outros. Embora alguns desses homens de museus também tivessem se dedicado à escrita de textos, modo tradicional de construção e divulgação do conhecimento histórico, por escrita da história considero aqui as práticas museológicas acima mencionadas e que implicam em seleção de aspectos do passado para a conformação de coleções e na criação de narrativas e representações da história, consubstanciadas nas exposições de documentos, sejam estes textos, imagens ou artefatos e que situam o museu de história como um dos lugares de mediação com o passado (BANN, 1994).

Entretanto, além da preocupação com escritos, imagens e artefatos, alguns desses primeiros historiadores também direcionaram sua atenção para a preservação arquitetônica ou dos monumentos, a exemplo da Inspetoria de Monumentos Nacionais, criada em 1934 por Gustavo Barroso à frente do Museu Histórico Nacional (MAGALHÃES, 2017). O projeto de Barroso fora suplantado pelos modernistas articulados em torno de Capanema e do processo de criação do SPHAN, quando o grupo protagonista se deslocou para escritores, advogados, e especialmente arquitetos, embora o qualificativo histórico conste na própria denominação daquela agência 
e a atribuição do denominado valor histórico seja objeto de suas narrativas e práticas (CHUVA, 2009).

No Rio Grande do Sul, Eduardo Duarte e Dante de Laytano, ambos pertencentes ao IHGRGS e ao Museu Júlio de Castilhos, participaram, em 1932, do projeto nacional desta Inspetoria, quando este último realizou o levantamento dos monumentos da cidade de Rio Pardo (ZAMIN, 2006).

A partir da criação do Serviço do Patrimônio Histórico e Artístico Nacional, foram designados interlocutores estaduais, responsáveis pelas questões atinentes ao patrimônio e à agência nacional. No caso do Rio Grande do Sul é digna de nota a atuação do historiador Dante de Laytano. Sobre esse último é interessante observar que teve uma atuação na universidade e também nas questões relacionados ao patrimônio, bem como no Museu Júlio de Castilhos. Segundo Letícia Nedel (1999), Dante de Laytano começou a destacar-se na década de 1930, quando ingressara no IHGRGS e no Museu Júlio de Castilhos. Em 1944, ingressou na vida acadêmica, onde teve papel importante na fundação das primeiras faculdades de Filosofia do estado. Dante de Laytano intermediou as solicitações de tombamento feitas pelos municípios, sendo o interlocutor e colaborador de Rodrigo Melo Franco de Andrade no estado. Por sua atuação, o Museu Júlio de Castilhos caracterizou-se, entre os anos 1954 e 1956, como uma "oficiosa delegacia regional" (NEDEL, 1999, p. 149) do órgão nacional.

Entre os anos 1950 e 1970, quando se intensificaram os movimentos pela preservação do patrimônio urbano em Porto Alegre (POSSAMAI, 2001), as vozes que se levantaram na defesa dos vestígios arquitetônicos e artísticos eram de arquitetos, jornalistas, escritores, advogados, vereadores, historiadores, membros do poder público, municipal entre outros agentes que permitiram justamente considerar o conceito de campo de Pierre Bourdieu (1989; 1996) operacional para analisar esse processo. Quando se concretizara a criação do Conselho de Patrimônio Histórico e Artístico de Porto Alegre, em 1976, foi assegurado assento especialmente para as representações de profissionais que, de alguma forma, haviam se envolvido com a questão até então, a exemplo do Instituto Histórico e Geográfico 
do Rio Grande do Sul, da Associação Rio-Grandense de Imprensa e do Instituto dos Arquitetos do Brasil.

Frinéia Zamin (2006), em investigação sobre a patrimonialização dos bens arquitetônicos pelo Instituto do Patrimônio Histórico e Artístico do Estado do Rio Grande do Sul (IPHAE), mostra que valor histórico era uma atribuição presente nas justificativas para o tombamento de inúmeras edificações, entre as décadas de 1980 e 1990. Os argumentos para afirmar a relevância histórica poderiam estar relacionados à historicidade arquitetônica do bem, ao aspecto do edifício ter sido moradia de personagens ou cenário de acontecimentos do passado rio-grandense, entre outros. Conforme demonstra a autora na análise dos processos de tombamento de 86 bens, esses pareceres contendo justificativas de ordem histórica, foram produzidos por historiadores, vários pertencentes ao Instituto Histórico e Geográfico do Rio Grande do Sul (IHGRGS), mas também por profissionais de outros ofícios envolvidos com a preservação patrimonial, entre os quais se sobressaiu a presença de arquitetos.

Desse modo, no caso do Rio Grande do Sul e de Porto Alegre, é possível perceber uma predominância de atuação dos membros do IHGRGS como porta-vozes autorizados da História. Entretanto, também há interseções da atuação de historiadores no âmbito acadêmico, bem como nas questões relacionadas ao patrimônio, aos arquivos e aos museus, especialmente a partir de um lugar consagrado, como é exemplo Dante de Laytano. Essas intersecções alteram-se ao longo das próximas décadas? Há um distanciamento do patrimônio da disciplina acadêmica ou da formação de futuros profissionais de História? Será que efetivamente isso ocorreu? Se ocorreu, quais as razões para isso? Essas razões podem ser localizadas no desenvolvimento interno da disciplina ou podem ser rastreadas na própria relação da disciplina com esse campo? Passou a haver uma resistência dos historiadores em jogar no campo das disputas políticas, deixando-as a outros profissionais? Quais os matizes locais e nacionais dessas mudanças? Acredito que ainda não tenhamos respostas a essas indagações e ainda precisaríamos avançar nas investigações empíricas para dar conta delas. Entretanto, 
arrisco-me aqui apenas a fazer algumas problematizações e lançar algumas hipóteses.

A primeira hipótese sugere que a atuação no campo do patrimônio esteve associada à escrita de uma história a partir de um lugar atrelado ao Estado. Museu, arquivo e órgãos de preservação, como o SPHAN e IPHAE, aqui mencionados, foram concebidos como agências estatais de escrita de uma história vinculada aos interesses de representação identitária, cujos pressupostos não eram compartilhados por uma história acadêmica ${ }^{1}$ que se gestava nas universidades.

A discussão sobre memória pela historiografia brasileira, parece dar algumas pistas do modo como as problemáticas poderiam ser tratadas de modo diverso. Nesse contexto, a obra Lugares de Memória, organizada por Pierre Nora $(1984 ; 1993)$ e publicada na França em 1984 (cuja tradução e publicação da introdução ocorre em 1993, no Brasil) pode ter sido um divisor de águas, a partir do qual todas essas coisas do passado, inventadas como símbolos identitários pelo Estado em diferentes contextos, puderam ser revisitadas no sentido da investigação com base na operação historiográfica (CERTEAU, 2011).

A obra Lugares de Memória caracterizou-se como um empreendimento editorial e intelectual do historiador Pierre Nora e buscou, por ocasião do bicentenário da Revolução Francesa, realizar um extenso levantamento dos lugares de criação e debate sobre a memória da França. Segundo Janice Gonçalves (2012), Lugares de Memória partiu da constatação do acelerado desaparecimento da memória nacional francesa e da onda comemorativa pulverizada pela multiplicidade de identidades singulares. Era intenção de Nora distanciar-se de uma narrativa calcada na memória da nação e proceder a uma "história da história", na qual os procedimentos do ofício pudessem ser descontruídos com vistas a serem percebidos seus vínculos estreitos com as operações da memória. Entretanto, como toda criação, esta fugiu ao domínio de seu criador e o próprio autor precisou avaliar o itinerário de apropriação de sua obra e os resultados fecundos ou abusivos da utilização da categoria lugares de memória.

Para o escopo desse texto, importa especialmente considerar como as relações entre história e memória propostas por Pierre Nora 
foram férteis para pensar as apropriações celebrativas presentes nos espaços consagrados dos museus, arquivos, patrimônios e memoriais. Embora a expressão "lugares de memória" tenha suscitado apropriações diversas, ora associado ao patrimônio edificado, ora usado para reforçar o viés comemorativo que tentava criticar (GONÇALVES, 2012), proporcionou ao historiador a ilusão da possibilidade de um distanciamento crítico entre história e memória e de seus dispositivos celebrativos e comemorativos, consubstanciados em uma variedade extremamente ampla, tais como manuais, monumentos, espaços, imagens, museus, efemérides.

Ao longo de vários anos de sua leitura, a obra de Nora foi examinada em suas imprecisões, a noção de lugares de memória foi problematizada, assim como as relações pretendidas entre história e memória foram criticadas por pressupor a possibilidade de distanciamento entre ambas (RICOEUR, 2001). Pela ótica proposta, a memória poderia deixar de ser objetivo para se tornar objeto de investigação da história (MENESES, 1992), acrescidas das devidas ressalvas explicitadas por outros autores (RICOEUR, 2001; CATROGA, 2001), no que se refere às implicações entre ambas, as quais nenhum pesquisador poderia ser ingênuo ao ponto de ignorá-las.

Mesmo que tenhamos avançado no sentido de compreender as implicações inevitáveis entre história e memória, a perspectiva epistemológica proposta por Lugares de memória, ao menos na introdução traduzida ao português, deixou um legado da necessidade de busca de distanciamento crítico em relação aos dispositivos materiais ou simbólicos erigidos no presente para fazer perdurar aspectos do passado. O patrimônio deixou de ser tão somente ação das agências do Estado, museus e outros órgãos, comprometida com uma determinada escrita da história e passou, paulatinamente, a figurar entre outros tantos objetos com legitimidade nas investigações dos programas de pós-graduação em história.

Além disso, considero relevante a entrada em cena da vertente da História Cultural e sua aproximação com a Antropologia, pois esta proporcionou o substrato teórico e metodológico para a acolhida de objetos até então inusitados para a historiografia, como patrimônio, monumentos, museus ou arquivos. Por um lado, a História Cultural permitiu investigar essa nova temática pela 
simples razão de jamais excluir qualquer possibilidade de estudo que permita aproximações com o passado ou seja, por considerar que todos os rastros, vestígios e traços deixados pela humanidade serve de material para o nosso ofício. Por outro lado, ofereceu abordagem metodológica capaz de proporcionar a compreensão desses fenômenos. Assim, a descrição densa (GEERTZ, 1989), o paradigma indiciário (GINZBURG, 1989) e a perspectiva da micro-história (GINZBURG, 1987; LEVI, 1992) permitiram buscar vestígios e traços de pouca visibilidade e analisar situações em âmbito local, como os processos de urbanização e de destruição/preservação de traços materiais nas cidades. Além disso, os conceitos de práticas, representações e imaginário (CHARTIER, 1990; BACZKO, 1991; PESAVENTO, 1995), entre outros, permitiram abordar as práticas e narrativas de sujeitos, instituições e grupos que de outro modo estariam esmaecidos em análises estruturantes ou em macro análises. Nesse sentido, não é à toa que os primeiros estudos históricos sobre o patrimônio e os museus no Brasil tenham sido inspirados em investigações oriundas especialmente da Antropologia, embora no exterior já estivessem presentes em obras historiográficas como Lugares de Memória, mencionada anteriormente.

Desse modo, observo um hiato que ainda necessita de maiores investigações para explicar como da onda comemorativa e celebrativa, com os historiadores comprometidos com uma determinada escrita a partir das agências do Estado e dos Institutos Históricos e Geográficos, a academia relegou esses temas e os retomou mais recentemente, a partir da lente dos usos do passado ou dos lugares de memória.

\section{O lugar do patrimônio na História acadêmica recente}

Pistas para compreender o reencontro da História com os estudos sobre o patrimônio podem ser encontradas no movimento de "inflação patrimonial” (HEINICH, 2012), situada especialmente após as décadas de 1970-1980, cujas atuações internacionais da Organização das Nações Unidas para a Educação, a Ciência e a Cultura (UNESCO), do Conselho Internacional de Museus (ICOM) 
e do Conselho Internacional de Monumento e Sítios (ICOMOS) apresentam um papel relevante no estímulo à patrimonialização e à designação dos denominados patrimônios da humanidade (CHOAY, 1996), embora a história do patrimônio seja mais recuada no tempo (POULOT, 1998; 2009). No Brasil, os movimentos pela preservação do patrimônio apresentam temporalidades diversas e descontinuidades, como mostram as análises que contemplam as esferas nacionais, regionais e locais (CHUVA, 2009; NOGUEIRA, 2005; ZAMIN, 2006; POSSAMAI, 2001).

Contudo, um marco importante talvez possa ser localizado especialmente após a abertura política, pós-ditadura civil-militar, e com a Constituição de 1988, alcunhada de carta cidadã, por esta ampliar os direitos sociais e culturais dos diferentes grupos que compõem a nacionalidade. Assim, multiplicaram-se no País os debates, reivindicações e movimentos em prol do direito à memória e ao patrimônio (SÃO PAULO, 1992; CONGRESSO, 1992), com a entrada em cena de diferentes atores sociais e culturais, entre os quais, como não poderia deixar de ser, também estavam os historiadores, preocupados especialmente com a preservação (e acesso!) dos traços do passado utilizados em seu ofício, cujo risco de conservação poderia gerar sociedades amnésicas e sem passado.

No âmbito específico dos estudos históricos, a inserção das questões relacionadas à memória, à cultura e ao patrimônio nos currículos de formação dos futuros historiadores certamente configurou aspecto que veio a incrementar a relação acadêmica com esse campo. No final dos anos 1990, os Parâmetros Curriculares Nacionais (PCNs) da educação básica definiram não apenas a necessidade de valorizar o patrimônio e a diversidade cultural brasileira, quanto situou essa exigência como forma de fortalecimento da cidadania e da democracia. Desse modo, foram necessários investimentos por parte das instituições universitárias na criação de disciplinas, nas reformulações curriculares e na incorporação de bibliografias e estudos específicos, no sentido de atender essas premissas formais (POSSAMAI; GIL, 2014).

Embora essas pistas ainda sejam rarefeitas e apresentadas aqui de modo muito preliminar, para os limites deste artigo, considero interessante apresentar os resultados de levantamento ${ }^{2}$ dos estudos 
sobre a temática patrimônio no Catálogo de Teses e Dissertações da Capes $^{3}$ e também a presença dessa temática nos Simpósios Nacionais de História, promovidos pela Associação Nacional de História ${ }^{4}$, de modo a visualizar a situação brasileira nesse escopo.

No Catálogo de Teses e Dissertações da CAPES foram localizados $^{5} 76$ trabalhos, no intervalo entre 2000 e 2010. O crescimento do número de dissertações e teses defendidas no Brasil foi considerável, passando de 2 trabalhos, localizados no ano de 2000, para 15 trabalhos, localizados no ano de $2009^{6}$. Certamente uma das razões desse crescimento decorre do aumento do número de programas de pós-graduação no País nesse intervalo, pois de 1.439 programas de pós-graduação avaliados pela CAPES em 2000, em 2010 esse número chega a 2.840 (BRASIL, 2017).

Ao observar a origem geográfica desses trabalhos, foi possível constatar uma recorrência de estudos oriundos de Goiás, com 26\%; Rio Grande do Sul, com 20\% e Rio de Janeiro, com 14\%. O destaque a esses estados pode estar relacionado à presença de formações multidisciplinares específicas sobre memória social, patrimônio ou assuntos correlatos, que foram criadas nesses três estados. Os demais estados presentes obtiveram percentuais inferiores a 10\%, sendo São Paulo com 7\%; Pernambuco, Distrito Federal e Espírito Santo, com 4\%; Rondônia, Bahia, Minas Gerais, Pará, Paraná e Paraíba, com 3\%; Ceará, Amazonas, Piauí, Maranhão e Santa Catarina, com 1\%.

Tendo em vista que o Catálogo onde foram buscados esses dados abrange todas as áreas da pós-graduação do sistema nacional, incluindo os mestrados multidisciplinares e profissionais, foi interessante constatar que 44\% desses estudos estão situados em programas de pós-graduação em Educação; 17\% estão localizados em programas de pós-graduação profissionais e 7\% estão localizados em programas de pós-graduação em História. Esses resultados demonstram que a maior incidência de estudos se localiza em programa com forte marca multidisciplinar, como é o caso da Educação e dos programas profissionais. Entretanto, é digno de nota o percentual de $7 \%$ de presença dessas investigações nos programas disciplinares de História.

Dos estudos identificados, 65\% constituem-se em dissertações acadêmicas; 29\% dissertações profissionais; 6\% teses, o que está de 
acordo com os dados anteriores sobre os estudos localizados em programas profissionais e da Educação. $\mathrm{O}$ número ainda pequeno de teses pode sugerir a incipiência de estudos nesse nível ou a fuga dos pesquisadores que produziram no mestrado sobre a temática para outros objetos na realização da tese.

No sentido de investigar a presença da temática especificamente na área de História, foi realizado um levantamento nos Anais dos Simpósios Nacionais de História. Esse segundo levantamento ${ }^{7}$ foi feito apenas nos anos ímpares, quando ocorreram os eventos bienais, entre 1999 e 2011, diretamente no site da Associação Nacional de História, no qual constam os anais à disposição para pesquisa na internet. Nesse intervalo de 13 anos, foram localizados 438 trabalhos publicados sobre patrimônio, educação patrimonial, museus ou educação em museus, foco da pesquisa. $\mathrm{O}$ número de trabalhos encontrado para os anos levantados foram: 1999, 37 trabalhos; 2001, 23 trabalhos; 2003, 56 trabalhos; 2005, 84 trabalhos; 2007, 83 trabalhos; 2009, 69 trabalhos e 2001, 86 trabalhos. Esses números são surpreendentes, principalmente, ao levar-se em conta que participam dos Simpósios Nacionais preponderantemente associados historiadores, embora também haja a participação de muitos estudantes de História não associados ou profissionais de outras áreas que apresentam trabalhos em interlocução com a História ${ }^{8}$. Esses números demonstram uma atenção considerável por parte dos estudos históricos para a temática do patrimônio, a partir de $1999^{\circ}$. Embora não tenhamos dados sistematizados para os anos subsequentes a 2011, é possível conjecturar que esses números tendem ao crescimento, pois passaram a ser oferecidos, no evento nacional, simpósios temáticos ${ }^{10}$ específicos sobre a temática ou que de alguma forma dialogavam com essa problemática, tais como as questões relacionadas aos arquivos e aos museus. Alguns simpósios temáticos têm sido oferecidos de modo sistemático e, em alguns casos, seus coordenadores tem se preocupado com a publicação desses trabalhos sob formato de livro (CHUVA; NOGUEIRA, 2012; LEAL; PAIVA, 2014), o que tem proporcionado a compilação, reunião e visibilidade da produção acadêmica sobre a problemática do patrimônio. 
Assim, esses números demonstram um interesse crescente por parte dos pesquisadores acadêmicos, especialmente historiadores e historiadoras, em investigar as questões relacionadas ao patrimônio. Levantamentos qualitativos necessitam ainda ser realizados no sentido de analisar as abordagens e problemáticas específicas selecionadas por esse amplo conjunto de trabalhos.

\section{O campo do patrimônio como espaço de ação cultural e política}

Finalmente, gostaria de retornar às minhas considerações iniciais sobre o lugar da história no campo do patrimônio, tendo em vista questões do momento atual.

Desde que venho refletindo sobre o patrimônio, realizando investigações e, mais recentemente, orientando estudos sobre museus e patrimônio, o conceito de campo mostra-se operacional para pensar práticas e representações relacionadas a essa problemática. O conceito de campo foi inicialmente proposto pelo sociólogo francês Pierre Bourdieu $(1989 ; 1996)$ no sentido de fugir à delimitação de grupo (imigrantes, escravos etc.) para abordar o espaço de relações entre os sujeitos. Por outro lado, o conceito parece pertinente naqueles casos empíricos nos quais não se identificam figuras expressivas que poderiam ser analisadas a partir da categoria de intelectual ou mesmo de intelectual mediador (SIRINELLI, 2003; GOMES; HANSEN, 2016). O campo define-se com um espaço de interação relativamente autônomo, onde agentes ou instituições ocupam determinadas posições e estão em luta, agindo e sofrendo efeitos produzidos nos seus limites. $\mathrm{O}$ autor tenta delimitar e compreender, nessa perspectiva, o campo político, campo intelectual, campo artístico, campo científico, campo literário, entre outros.

O conceito foi apropriado por alguns autores como o antropólogo argentino radicado no México Nestor Garcia Canclini, para pensar as problemáticas especificamente relacionadas ao patrimônio cultural. Desse modo, esse autor definiu patrimônio como "espacio de lucha material y simbólica entre las clases, las etnias y los grupos" 
(CANCLINI, 1992, p. 182). Em aproximações empíricas, no Brasil, autores como Maria Cecilia Londres Fonseca (1997) utilizaram o mesmo conceito para enquadrar os intelectuais modernistas e homens públicos envolvidos com a política cultural do Serviço do Patrimônio Histórico e Artístico Nacional, desde 1937. No Rio Grande do Sul, um dos primeiros estudos acadêmicos produzidos sobre o patrimônio, no Programa de Pós-Graduação em Antropologia Social, abordou o processo de preservação das casas de madeira de Antônio Prado e definiu o campo do patrimônio como "[...] um sistema de relações objetivas entre os agentes sociais encarregados das tarefas práticas e simbólicas ligadas ao tombamento e preservação de bens culturais" (LEWGOY, 1992, p. 71).

Além do viés relacionado à preservação do patrimônio edificado, tentei imaginar o conceito de campo do patrimônio de modo a incluir os museus, pois seus agentes compartilham práticas e representações daqueles atores que interferem na conservação arquitetônica. Nesse caso, os agentes lidam não apenas com o objeto arquitetônico ressignificado e utilizado como sede de muitos museus brasileiros, mas também com coleções materiais e visuais a partir das quais colocam em jogo os procedimentos de uma cadeia operatória que envolve práticas de conservação, documentação, pesquisa e exposição. Anteriormente (POSSAMAI, 2001), sugeri a delimitação de um sub-campo dos museus, a partir do que Bourdieu $(1989 ; 1996)$ pensou como sub-campo do sindicato e do partido, no interior do campo político. No Brasil, a partir da Política Nacional de Museus (BRASIL, 2007) tornou-se corrente a utilização da expressão campo museal, cuja tentativa de definição pode ser sugerida como espaço de relações onde atuam os agentes envolvidos com as práticas museológicas e patrimoniais a ele vinculados. Com vistas à diferenciação da noção disciplinar de campo museológico, o campo dos museus pode ser pensado como espaço onde interagem sujeitos provenientes de diversas formações disciplinares (Museologia, História, Antropologia, Educação, Arquitetura, Biologia etc.), além de agentes do poder público, instituições, associações, pessoas e grupos envolvidos com as problemáticas atinentes à musealização ou à patrimonialização da memória. 
Aqui caberia elucidar sobre a operacionalidade do conceito de campo para auxiliar a pensá-lo para o patrimônio. Pierre Bourdieu enfatiza que o campo não se restringe a um recorte corporativo embora o espaço profissional possa funcionar como campo, mas um espaço de relações entre diferentes sujeitos que disputam o poder de construir, instituir e difundir práticas e representações. No caso do patrimônio, essas práticas e representações agem sobre os bens culturais. O campo do patrimônio, desse modo, é necessariamente pluridisciplinar por congregar profissionais de áreas diversas, como História, Arquitetura e Urbanismo, Antropologia, Direito, Arquivologia, Biblioteconomia, Museologia, entre muitas outras. Não se alcançou, ainda, a configuração disciplinar desse campo, embora no Brasil possa ser observada a criação de inúmeras formações multidisciplinares em nível de pós-graduação tendo nos seus títulos termos como patrimônio, bens culturais, memória social, educação patrimonial, entre outras. Talvez essas iniciativas sejam anúncios do imperativo de abordagem transdisciplinar de uma problemática que não se restringe às perspectivas disciplinares correntes.

Portanto, para aproximações a esse objeto de estudo, em muitos contextos temporais, o viés disciplinar é absolutamente insatisfatório, pois o patrimônio caracteriza-se historicamente por agregar diferentes interações, abordagens e procedimentos oriundos de diversas áreas de conhecimento. No caso da História, o estudo das práticas relativas à conservação das coisas materiais pode indicar pistas sobre a configuração do ofício do historiador, como visto anteriormente. Em muitos casos, na medida em que a patrimonialização interfere nos processos de construção de memórias e esquecimentos de grupos, instituições e pessoas, tomam parte no campo do patrimônio outros agentes para além do recorte profissional ou acadêmico. $\mathrm{O}$ patrimônio assim, mobiliza um sem número de sujeitos nos diferentes contextos espaciais e temporais.

Finalmente, é relevante mencionar que a configuração dos patrimônios se processa por meio de narrativas discursivas e pelo estabelecimento de determinadas práticas. São práticas e representações, assim, que definem os patrimônios. As narrativas discursivas, por seu turno, atribuem determinados valores de ordem histórica, artística, arquitetônica, antropológica, que colaboram na instituição 
dos patrimônios. Digo "colaboram" por considerar que essas narrativas não tem o poder exclusivo sobre a decisão de configuração dos patrimônios. Quase sempre os pesquisadores se debruçam sobre narrativas que obtiveram eficácia e sucesso no sentido da preservação. Entretanto, outras narrativas, de mais difícil aproximação, foram ineficazes, levando a destruições. Exemplo em Porto Alegre é o destombamento da Igreja do Rosário, um dos raros remanescentes do século XVIII da cidade, processo oriundo das relações entre Getúlio Vargas e o Bispo da época. Além desse exemplo histórico, minha experiência com a gestão do patrimônio urbano me permitiu verificar in loco que o campo político tem o poder decisório final sobre o campo do patrimônio, intersecção que mereceria maiores investigações em diferentes contextos. Pode-se, talvez, afirmar que quanto menos democrático o processo, maior é o poder do campo político nessa institucionalização.

Assim, muitos estudos sobre os processos patrimoniais referem-se justamente a períodos autoritários, por terem sido nesses momentos da história política brasileira que as políticas públicas relacionadas ao patrimônio receberam grande investimento. Desse modo, vários autores analisam a criação e consolidação do SPHAN em estreita relação com a política nacionalista do Estado Novo (CHUVA, 2009). Os meandros das disputas políticas intraburocráticas ganham relevância nesse aspecto. Num caso local, Porto Alegre, os movimentos pela preservação nos anos 1970, momento da ditadura civil-militar, partem da sociedade, de determinados agentes que utilizam canais de divulgação, a imprensa escrita especialmente, e conseguem fazer valer suas ideias no âmbito do poder público municipal. Nesse último caso, as tensões entre o campo político e o campo do patrimônio são flagrantes. $\mathrm{Na}$ história do patrimônio de Porto Alegre são diversos os exemplos, nos quais a narrativa pela preservação obteve eficácia e outros nos quais esta não obteve sucesso.

Após a abertura e a Constituição de 1988, conforme mencionado anteriormente, o quadro altera-se completamente, pois muitos grupos passam a liderar movimentos pela representação de suas memórias e patrimônios em nível local, regional ou nacional. A situação se complexifica, pois o campo alarga-se sobremaneira a 
ponto de termos que refletir se este conceito continua operacional para pensarmos as relações entre aqueles agentes que ainda são detentores do poder de instituir através de narrativas e práticas o que é considerado patrimônio e uma diversidade de indivíduos, muitas vezes organizados em movimentos, redes e associações, que pressionam o campo no sentido de interferir nessas políticas públicas.

Eu arrisco dizer que a adoção de políticas públicas de gestão participativa tem algo a ver com a intensificação desses movimentos. Vou dar o exemplo de Porto Alegre, que conheço um pouco melhor. Em Porto Alegre, quando inicia o Orçamento Participativo a iniciativa é do poder público de oferecer possibilidades nesse sentido (como o Projeto Memória dos Bairros que ainda merece ser estudado). Embora, no interior das agências estivéssemos discutindo como fazer para democratizar o processo de decisões sobre a institucionalização do patrimônio, várias instâncias continuavam e continuam engessadas, a exemplo do Conselho Municipal do Patrimônio Cultural de Porto Alegre, mencionado anteriormente.

Entretanto, a gestão democrática e participativa deixou sementes que frutificaram em inúmeras iniciativas oriundas de indivíduos, associações, grupos, moradores de determinados bairros, movimentos que reivindicam questões relativas ao patrimônio ambiental e urbano. Mais recentemente, as redes sociais incrementaram de modo exponencial essa problemática, fazendo com que se multipliquem os agentes envolvidos, se produzam imagens e narrativas sobre os processos que, por sua vez, apresentam um potencial de disseminação nunca antes visto. Desse modo, é possível perceber que são as relações entre o campo político e o campo do patrimônio, no qual se inclui uma pluralidade de sujeitos organizados em movimentos, redes, e associações, que irão conformar a preservação de determinados bens culturais. $\mathrm{Na}$ trama entre os interesses envolvidos com a conservação e a destruição, especialmente nos contextos urbanos, os sujeitos jogam com suas armas materiais ou simbólicas. Se em décadas passadas, esse era assunto para poucos homens de letras e raros homens de museus, hoje, uma pluralidade de sujeitos interferem e participam ativamente do debate e da luta em prol dos seus patrimônios e de suas memórias. 


\section{Considerações para continuar a pensar e agir}

As considerações aqui tecidas foram motivadas pela presença da problemática do patrimônio nos estudos históricos e na atuação de historiadores e historiadoras nesse campo. Percorrer no tempo as aproximações e distanciamentos da História com essas questões auxilia a pensar que esse não era um assunto assim tão estranho à historiografia, de modo a considerar o patrimônio um objeto pertinente ao conhecimento histórico, bem como reservar um lugar de prestígio à História na arena de disputas que caracteriza o campo do patrimônio.

Como visto, a História sempre esteve e continua presente nesse campo, por meio dos Institutos, por exemplo, cujo serviço em prol da preservação do patrimônio brasileiro, é inestimável. Mais do que uma disputa pelo olhar disciplinar, importa incorporar aos debates relativos ao patrimônio aspectos que a história também passou a privilegiar nas muitas mudanças operadas ao longo dos anos. Se no século XIX importava uma narrativa linear comprometida com a construção de identidades, hoje a história parece estar mais preocupada com a mudança e as diferenças. Assegurar que os nossos patrimônios sejam vistos dessa perspectiva, implica em valorizar questões e aspectos do passado negligenciados, bem como refletir sobre os modos como esse passado, materializado em patrimônio, permanece no presente.

Se isso parece ser muito, entretanto, não é suficiente. Se o patrimônio se constitui em campo de disputa, esse jogo a ser jogado necessita de atores, entre os quais também os historiadores, arquitetos, museólogos, artistas, advogados, biólogos e muitos outros profissionais. Mas numa sociedade democrática, isso não basta, pois ainda é imperativo que mais pessoas se envolvam e considerem o patrimônio assunto de reflexão, debate e decisão de uma coletividade maior. Se assim não for, o patrimônio estará submetido a lógicas que não necessariamente consideram a cultura, a memória e a história como fortalezas individuais e coletivas. 


\section{THE PLACE OF HERITAGE IN THE HISTORIOGRAPHICAL OPERATION AND THE PLACE OF HISTORY IN THE FIELD OF HERITAGE}

Abstract: This article discusses some issues about the place of heritage in the historiographical operation and the place of history, as writing and as political action, in the field of heritage. Initially, it argues that history and historians were interested in practices of heritage in Brazil. Secondly, the results are shown of research in Brazilian academic production about heritage, between 1999 and 2011, especially in historical studies of post-graduation. Finally, it is discussed the concept of field of heritage and political field to think the people involved with this issue. Conclude that history and historians were involved with issues of heritage, since the emergence of first Brazilians museums, in the XIX century. In this context, the writing of history was connected with the Historical and Geographical Institutions. Recently, the heritage was resumed by academic history as a subject of research and by historians as the political action.

Keywords: Heritage. Writing of history. Museums. Field.

\section{Notas}

${ }^{1}$ Por história acadêmica compreende-se a produção de conhecimento histórico produzido a partir das universidades, especialmente consolidada, no Brasil, a partir da implantação dos programas de pós-graduação.

${ }^{2}$ Levantamento realizado no âmbito do Projeto de Pesquisa Memória, Patrimônio e Educação, coordenado pela autora.

${ }^{3}$ A Coordenação de Aperfeiçoamento de Pessoal de Nível Superior é uma fundação do Ministério da Educação (MEC) do Brasil, responsável pela gestão da pós-graduação stricto sensu (mestrado e doutorado) em todos os estados da Federação. Entre suas diversas competências e programas, a CAPES mantem em seu site na rede mundial de computadores um Catálogo de Teses e Dissertações, contendo os trabalhos defendidos em todos os programas de pós-graduação no Brasil. No momento da escrita desse artigo, o referido site poderia ser localizado em: 〈http://catalogodeteses.capes.gov.br/catalogo-teses/\#!/>.

${ }^{4}$ Criada em 1961 como Associação Nacional de Professores Universitários de História. A ampliação de seus associados de modo a incluir professores do ensino básico e profissionais atuantes em instituições de patrimônio e memória espalhadas por todo o país levou à nova denominação de Associação 
Nacional de História, a partir de 1993. Para maiores informações, consultar o site 〈https://anpuh.org.br〉.

${ }^{5}$ Foram utilizados para busca no referido Catálogo de Teses e Dissertações da CAPES, os termos "patrimônio" e "educação patrimonial".

${ }^{6}$ Considerei aqui os dados para o ano de 2009 , tendo em vista que o levantamento fora realizado em 2010, ainda não estando esse ano fechado para a inserção de novos trabalhos no banco de dados.

${ }^{7}$ Nesse segundo levantamento, foram buscados os termos "patrimônio", "educação patrimonial" e "museus" nos títulos e resumos dos trabalhos apresentados e publicados nos Anais.

${ }^{8}$ O Parágrafo Primeiro do Artigo 12 dos Estatutos da ANPUH define que "Serão admitidas como associadas as pessoas físicas que (i) sejam graduadas em cursos de História, devidamente aprovados pelo Ministério da Educação; (ii) sejam pós graduadas ou estejam cursando a pós graduação em História ou em cursos que tenham área de concentração em História, devidamente aprovados pelo Ministério da Educação; (iii) tenham publicado trabalhos em qualquer ramo da História, ou que atuem em áreas afins a ela, desde que recomendadas por uma Seção Estadual e referendadas pela Diretoria Nacional da Associação. Disponível em: 〈http://anpuh.org/estatuto>.

${ }^{9} \mathrm{O}$ levantamento ainda buscou os estudos específicos na interface entre educação e patrimônio, tendo sido identificados 34 trabalhos desse total de 438, entre 1999 e 2011. Da mesma forma, os números vão em ordem crescente: um trabalho apresentado em 1999 e 10 trabalhos apresentados em 2011 sobre essa problemática. Dessas 34 publicações, 10 tratam especificamente sobre educação em museus.

${ }^{10}$ Apenas para o Simpósio Nacional de História do ano de 2017 foram oferecidos 6 simpósios temáticos sobre patrimônio, a saber: As condições históricas das legislações sobre o patrimônio cultural; Da construção dos patrimônios ao acesso às cidades: direitos, negociações e conflitos; Narrativas de florestas e cidades amazônicas: patrimônios, histórias e literaturas em trânsitos orais, escritos e visuais; Patrimônio cultural: educação e novas tecnologias; Patrimônio, memória e cidadania; Um balanço dos museus em tempos de crise: novos atores e novas questões ou a celebração do mesmo? 
O lugar do patrimônio na operação historiográfica e o lugar da história...

\section{Referências}

ABREU, Regina. A fabricação do imortal: memória, história e estratégias de consagração no Brasil. Rio de Janeiro: Lapa; Rocco, 1996.

BACZKO, Bronislaw. Los imaginarios sociales, memórias y esperanzas colectivas. Buenos Aires: Ediciones Nueva Visión, 1991.

BANN, Stephen. As invenções da história: ensaios sobre a representação do passado. São Paulo: Ed. UNESP, 1994.

BITTENCOURT, José Neves. Memória para o futuro: o Instituto Histórico e Geográfico Brasileiro e seu museu (1839-1889). Anais do Museu Histórico Nacional, Rio de Janeiro, v. 37, p. 195-219, 2005.

BOURDIEU, Pierre. O poder simbólico. Rio de Janeiro: Difel, 1989. . As regras da arte. São Paulo: Companhia das Letras, 1996.

BRASIL. Ministério da Cultura. Instituto do Patrimônio Histórico e Artístico Nacional. Departamento de Museus e Centros Culturais. Política Nacional de Museus. Brasília, DF, 2007.

. Ministério da Educação. Coordenação de aperfeiçoamento de pessoal de ensino superior (Capes). Geocapes: Sistema de Informações Georeferenciadas. Brasília, DF, 2017. Disponível em: 〈https://geocapes.capes.gov.br/geocapes/>. Acesso em: 21 set. 2018.

BREFE, Ana Claudia Fonseca. Museu Paulista: Affonso de Taunay e a memória nacional. São Paulo: Editora UNESP; Museu Paulista, 2005.

CANCLINI, Néstor García. Culturas híbridas: estratégias para entrar y salir de la modernidad. Buenos Aires: Editorial Sudamericana, 1992.

CARNEIRO, Cíntia Braga. O Museu Paranaense e Romário Martins: a busca de uma identidade para o Paraná. Curitiba: SAMP, 2013.

CATROGA, Fernando. Memória e história. In: PESAVENTO, Sandra (Org.). Fronteiras do milênio. Porto Alegre: Editora da Universidade, 2001. p. 43-69.

CERTEAU, Michel. A escrita da História. 3. ed. Rio de Janeiro: Forense, 2011. CHAGAS, Mário de Souza. A imaginação museal: museu, memória e poder em Gustavo Barroso, Gilberto Freyre e Darcy Ribeiro. Rio de Janeiro: MINC/ IBRAM, 2009.

CHARTIER, Roger. A nova história cultural: entre práticas e representações. Lisboa: Difel, 1990.

CHOAY, Françoise. L’allégorie du patrimoine. Paris: Seuil, 1996.

Anos 90, Porto Alegre, v. 25, n. 48, p. 23-49, dez. 2018 
CHUVA, Márcia Regina Romeiro. Os arquitetos da memória: sociogênese das práticas de preservação do patrimônio cultural no Brasil (anos 1930-1940). Rio de Janeiro: UFRJ, 2009.

CHUVA, Márcia Regina Romeiro; NOGUEIRA, Antonio Gilberto Ramos. Patrimônio Cultural: políticas e perspectivas de preservação no Brasil. Rio de Janeiro: Mauad, 2012.

CONGRESSO LATINO-AMERICANO SOBRE A CULTURA ARQUITETÔNICA E URBANÍSTICA, PATRIMÔNIO AMBIENTAL URBANO E QUALIDADE DE VIDA, 2., 1972, Porto Alegre, RS. Anais... Porto Alegre: Prefeitura Municipal, 1992.

FARIA, Ana Carolina Gelmini de. Educar no museu: o Museu Histórico Nacional e a educação no campo dos museus (1932-1958), 2017. 296p. Tese (Doutorado)-Programa de Pós-Graduação em Educação da Universidade Federal do Rio Grande do Sul, Porto Alegre, 2017.

FONSECA, Maria Cecília Londres. O patrimônio em processo: trajetória da política federal de preservação no Brasil. Rio de Janeiro: Ed. UFRJ; Ministério da Cultura; IPHAN, 1997.

GEERTZ, Clifford. A interpretação das culturas. Rio de Janeiro: Editora Guanabara, 1989.

GINZBURG, Carlo. Mitos, emblemas e sinais: morfologia e história. São Paulo: Companhia das Letras, 1989.

. O queijo e os vermes: o cotidiano e as ideias de um moleiro perseguido pela inquisição. São Paulo: Companhia das Letras, 1987.

GOMES, Angela de Castro. História e historiadores. Rio de Janeiro: Fundação Getúlio Vargas, 2013.

GOMES, Angela de Castro; HANSEN, Patricia Santos (Org.). Intelectuais mediadores: práticas culturais e ação política. Rio de Janeiro: Civilização Brasileira, 2016.

GONÇALVES, José Reginaldo Santos. A retórica da perda: os discursos do patrimônio cultural no Brasil. Rio de Janeiro: Editora UFRJ; IPHAN, 1996.

GONÇALVES, Janice. Pierre Nora e o tempo presente: entre a memória e o patrimônio cultural. Revista Historiae, Rio Grande, v. 3, n. 3, p. 27-45, 2012.

GUIMARÃES, Manoel Luís Salgado. Nação e civilização nos trópicos: o Instituto Histórico e Geográfico brasileiro e o projeto de uma história nacional. Estudos Históricos, Rio de Janeiro, n. 1, p. 5-27, 1988. 
HEINICH, Nathalie. La fabrique du patrimoine: de la cathédrale à la petite cuiliière. Paris: Maison des Sciences de L'homme, 2012.

JULIÃO, Letícia. Colecionismo, museu e identidade regional em Minas Gerais. In: GUIMARÃES, Manoel; RAMOS, Francisco (Org.). Futuro do Pretérito: escrita da História e História do Museu. Fortaleza: Instituto Frei Tito de Alencar, 2010. p. 294-312.

LEAL, Elisabete; PAIVA, Odair da Cruz. Patrimônio e história. Londrina: UNIFIL, 2014.

LEVI, Giovani. Sobre a micro-história. BURKE, Peter. A escrita da história: novas perspectivas. São Paulo: Editora da Unesp, 1992. p. 133-161.

LEWGOY, Bernardo. A invenção de um patrimônio: um estudo sobre as repercussões sociais do processo de tombamento e preservação de 48 casas em Antonio Prado/RS. Dissertação (Mestrado)-Universidade Federal do Rio Grande do Sul, Porto Alegre, 1992.

LOPES, Maria Margaret. O Brasil descobre a pesquisa científica. São Paulo: Ed. Hucitec, 2005.

LOPES, Maria Margaret; MURRIELLO, Sandra Elena. Ciências e educação em museus no final do século XIX. História, Ciências, Saúde - Manguinhos, Rio de Janeiro, v. 12, supl., p. 13-30, 2005.

MAGALHÃES, Aline Montenegro. Culto da saudade na Casa do Brasil: Gustavo Barroso e o Museu Histórico Nacional (1922-1959). Fortaleza: Museu do Ceará; Secretaria da Cultura do Estado do Ceará, 2006.

. A Inspetoria de Monumentos Nacionais do Museu Histórico Nacional e a proteção de monumentos em Ouro Preto (1934-1937). Anais do Museu Paulista, Nova Série, São Paulo, v. 25, n. 3, p. 233-290, set./dez. 2017.

MENESES, Ulpiano Bezerra de. A história, cativa da memória? Para um mapeamento da memória no campo das ciências sociais. Revista do Instituto de Estudos Brasileiros, n. 34, São Paulo, 1992, p. 9-24.

NEDEL, Letícia Borges. Paisagens da Província: o regionalismo sul-rio-grandense e o Museu Júlio de Castilhos nos anos cinqüenta. Dissertação (Mestrado em História)-Instituto de Filosofia e Ciências Sociais, UFRJ, 1999.

NOGUEIRA, Antonio Gilberto Ramos. Por um inventário dos sentidos: Mário de Andrade e a concepção de patrimônio e inventário. São Paulo: Hucitec, 2005. NORA, Pierre. Les lieux de mémoire. t. I (La République). Paris: Gallimard, 1984. . Entre memória e história: a problemática dos lugares. Projeto História, São Paulo, n. 10, p. 7-28, 1993. 
PESAVENTO, Sandra J. Em busca de uma outra história: imaginando o imaginário. Revista Brasileira de História, São Paulo, v. 15, n. 29, p. 9-27, 1995.

POSSAMAI, Zita. Nos bastidores do museu: patrimônio e passado da cidade de Porto Alegre. Porto Alegre: Est Edições, 2001.

.Visibilidades do passado: percursos das relações entre História e memória nos museus. In: GRAEBIN, Cleusa Maria Gomes; SANTOS, Nádia Maria Weber (Org.). Memória Social: questões teóricas e metodológicas. Canoas: UnilaSalle, 2013. p. 207-225.

POSSAMAI; GIL, Carmem. Educação Patrimonial: percursos, concepções e apropriações. Mouseion, Canoas, v. 19, p. 13-26, 2014.

POULOT, Dominique (Ed.). Patrimoine et modernité. Paris: L’Harmattan, 1998.

- Uma história do patrimônio no Ocidente, séculos XVIII-XXI: do monumento aos valores. São Paulo: Estação Liberdade, 2009.

RICOEUR, Paul. La mémoire, l'histoire, l'oubli. Paris: Seuil, 2001.

SANJAD, Nelson. A coruja de minerva: o Museu Paraense entre o Império e a República. Brasília, DF: IBRAM, 2010.

SANTOS, Myriam Sepúlveda dos. A escrita do passado em museus históricos: museu, memória e cidadania. São Paulo: Garamond, 2006.

SÃO PAULO. Secretaria Municipal da Cultura. Departamento do Patrimônio Histórico. O direito à memória: patrimônio histórico e cidadania. São Paulo, 1992.

SCHWARCZ, Lilia Moritz. O espetáculo das raças: cientistas, instituições e questão racial no Brasil, 1870-1930. São Paulo: Companhia das Letras, 2005.

SILVA, Ana Celina Figueira da. Investigações e evocações do passado: o Departamento de História Nacional do Museu Júlio de Castilhos (Porto Alegre/RS, 1925-1939), 2018, 332 p. Tese (Doutorado)-Programa de Pós-Graduação em História da Universidade Federal do Rio Grande do Sul, Porto Alegre, 2018.

SIRINELLI, Jean François. Os intelectuais. In: RÉMOND, René. Por uma história política. 2. ed. Rio de Janeiro: FGV, 2003. p. 231-269.

ZAMIN, Frinéia. Patrimônio cultural do Rio Grande do Sul: a atribuição de valores a uma memória coletiva edificada para o estado. Porto Alegre: UFRGS, 2006.

Recebido em: 07/06/2018

Aprovado em: 15/09/2018 
